\title{
Th1/Th17 polarization persists following whole-cell pertussis vaccination despite repeated acellular boosters
}

\author{
Ricardo da Silva Antunes, ${ }^{1}$ Mariana Babor, ${ }^{1}$ Chelsea Carpenter, ${ }^{1}$ Natalie Khalil, ${ }^{1}$ Mario Cortese, ${ }^{2}$ Alexander J. Mentzer, ${ }^{3}$ \\ Grégory Seumois, ${ }^{1}$ Christopher D. Petro, ${ }^{4}$ Lisa A. Purcell, ${ }^{4}$ Pandurangan Vijayanand, ${ }^{1,5}$ Shane Crotty, ${ }^{1,5}$ Bali Pulendran, ${ }^{2}$ \\ Bjoern Peters, ${ }^{1,5}$ and Alessandro Sette ${ }^{1,5}$ \\ 'Division of Vaccine Discovery, La Jolla Institute for Allergy and Immunology, La Jolla, California, USA. Department of Microbiology and Immunology, Stanford University School of Medicine, \\ Stanford, California, USA. ${ }^{3}$ Wellcome Centre for Human Cenetics, University of Oxford, Oxford, United Kingdom. ${ }^{4}$ Regeneron Pharmaceuticals Inc., Tarrytown, New York, USA. \\ ${ }^{5} U$ CSD School of Medicine, La Jolla, California, USA.
}

\begin{abstract}
In the mid-1990s, whole-cell pertussis (wP) vaccines were associated with local and systemic adverse events that prompted their replacement with acellular pertussis (aP) vaccines in many high-income countries. In the past decade, rates of pertussis disease have increased in children receiving only aP vaccines. We compared the immune responses to aP boosters in individuals who received their initial doses with either WP or aP vaccines using activation-induced marker (AIM) assays. Specifically, we examined pertussis-specific memory $\mathrm{CD}^{+} \mathrm{T}$ cell responses ex vivo, highlighting a type $2 /$ Th2 versus type $1 /$ Th1 and Th17 differential polarization as a function of childhood vaccination. Remarkably, after a contemporary aP booster, cells from donors originally primed with aP were (a) associated with increased IL-4, IL-5, IL-13, IL-9, and TCF- $\beta$ and decreased IFN- $\gamma$ and IL-17 production, (b) defective in their ex vivo capacity to expand memory cells, and (c) less capable of proliferating in vitro. These differences appeared to be T cell specific, since equivalent increases of antibody titers and plasmablasts after aP boost were seen in both groups. In conclusion, our data suggest that there are long-lasting effects and differences in polarization and proliferation of $\mathrm{T}$ cell responses in adults originally vaccinated with aP compared with those that initially received $\mathrm{wP}$, despite repeated acellular boosters.
\end{abstract}

\section{Introduction}

Before introduction of the pertussis vaccine, about 200,000 cases/year of whooping cough were reported in the US alone (1). A licensed pertussis vaccine that was introduced in the mid-1940s substantially reduced disease in vaccinated infants (but not adults) and was credited for a gradual pertussis incidence decline that reached fewer than 3,000 cases per year during 1980-1990. The original vaccine, composed of whole, inactivated bacteria adjuvanted with aluminium salts (alum; whole-cell pertussis [wP]) was phased out in the US due to the association of prominent local and systemic adverse effects. However, wP is still used in many countries around the world. The wP was replaced by the acellular pertussis $(\mathrm{aP})$ vaccine, a mixture of several different pertussis proteins and alum, which was universally adopted in the US in 1996 (2, 3). Additionally, pertussis vaccines have always been combined with diphtheria and tetanus toxoids (Clostridium tetani toxin, TT) since they were introduced for both priming at infancy (dipthera-tetanus-wP [DTwP] or dipthera-tetanus-aP [DTaP]) and

Related Commentary: p. 3742

Conflict of interest: The authors have declared that no conflict of interest exists. Submitted: March 26, 2018; Accepted: June 12, 2018.

Reference information: / Clin Invest. 2018;128(9):3853-3865.

https://doi.org/10.1172/JCl121309. as a booster vaccination (tetanus-diphtheria-acelluar pertussis [Tdap]) (1). Recent years have seen a dramatic uptick in the incidence of disease in countries where the aP vaccine is used exclusively despite effective initial protection (4-7). The reasons for this increase in disease incidence have not been fully elucidated, and several potential explanations have been suggested. Indeed, evolutionary shifts favoring novel alleles for virulence factors, poor vaccination rates, and/or vaccine refusals and detection bias due to enhanced diagnostic techniques have been proposed (8-11). Conversely, an emergent picture associated with differential mucosal immunity seems to offer a better explanation $(9,12-15)$; however, human studies are lacking.

The effectiveness of pertussis vaccination and duration of immunity are thought to correlate with both antibody and $\mathrm{T}$ cell responses. Humoral responses to $\mathrm{wP}$ and aP have been characterized previously (16-21). Interestingly, protection against infection persists even after antibody titers have decreased (22-24), suggesting that a cellular component contributes to immunity to Bordetella pertussis. Animal studies indicate that memory Th1 and Th17 $\mathrm{CD}^{+} \mathrm{T}$ cell responses to $B$. pertussis are required for long-lasting immunity, and significant responses in these subsets can be detected after wP vaccination and after infection (25-27). In humans, aP vaccination was reported to induce a predominant type $2 /$ Th2 polarized response (28-31), and several studies have proposed qualitative differences in the phenotype of $\mathrm{T}$ cell 
A
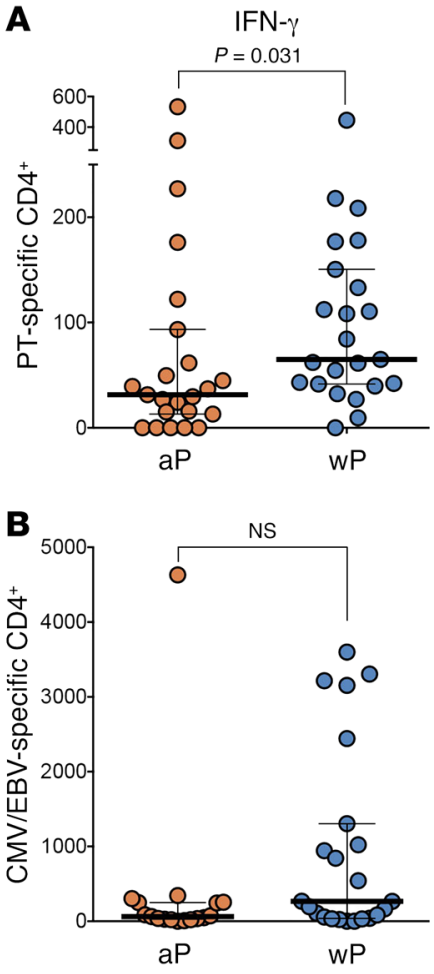
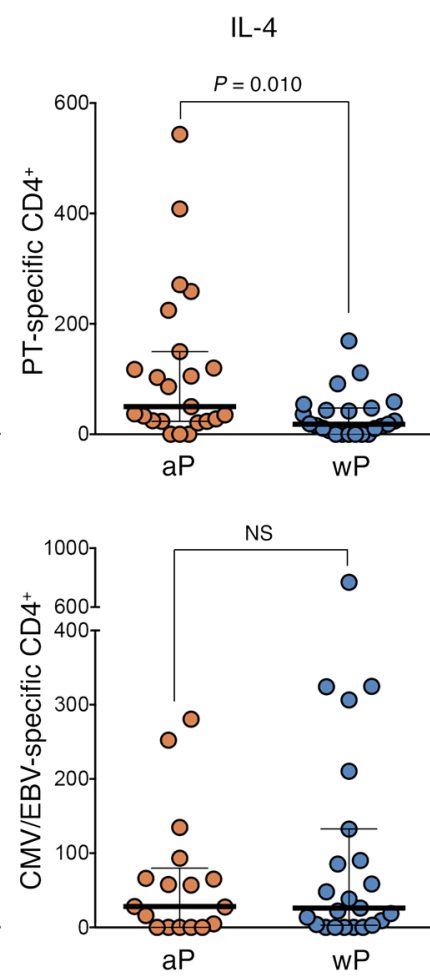

aP
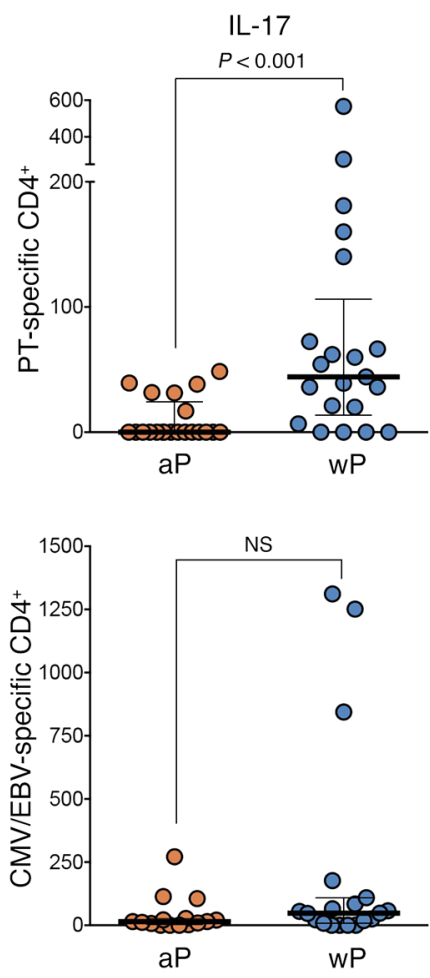

Figure 1. Differential polarization of PT-specific CD4 ${ }^{+} \mathrm{T}$ cells as a function of childhood vaccination. IFN- $\gamma-$, IL-4-, and IL-17-secreting cells were measured by ICS staining in PT- (A) or CMV/EBV-specific (B) $\mathrm{CD}^{+} \mathrm{T}$ cells by $\mathrm{AIM}_{25}$ assay. Responses represent the cohorts of donors originally DTaP or DTwP vaccinated, 1 to 3 months after Tdap-boosting vaccination. Each dot represents the number of total $\mathrm{CD}^{+} \mathrm{T}$ cells that were ascribed to each cytokine. For all panels, data are expressed as median \pm the interquartile range for each cohort and each data point represent a single donor ( $n=23$ for each cohort). $P$ value is shown as statistically significant by 2-tailed MannWhitney $U$ test. responses, resulting in less effective and/or durable responses as immunological mechanisms to explain the decreasing efficacy of aP vaccination (32-35).

The recent resurgence of pertussis is particularly associated with children aged 6 to 11 years or adolescents and young adults and has been linked to the waning of pertussis-specific immunity, despite the addition of a booster vaccination with the aP vaccine in this age bracket $(15,36-40)$. It would thus appear that a key difference or differences exist in pertussis immunity as a function of the original childhood vaccination with aP compared with wP. Based on disease incidence, this difference is only revealed over 1 or 2 decades despite continued boosts of both populations with aP (4-5 additional aP vaccinations are routinely administered in childhood and adolescence, and beginning in 1996, emergency room tetanus vaccinations in the US have often been given with vaccines containing an aP component) $(41,42)$. This "waning immunity" is of great concern (37), and it is challenging to address because it manifests itself more than 15 years after the first immunization. Thus, it would be important to define the mechanisms associated with waning immunity in order to guide modifications in vaccine composition, adjuvantation, or schedules and thus increase vaccine efficacy.

We recently characterized antibodies and $\mathrm{CD}^{+} \mathrm{T}$ cell responses to pertussis antigens in individuals originally vaccinated with either wP or aP using an in vitro and cross-sectional study approach (43). Notably, the differential Th polarization was maintained even in teenagers and adults. Since polarization is maintained for years after the original priming, even after identical boosting with aP $(35,43)$, data support the notions that wP priming enacts a differential molecular program in the vaccine-specific $\mathrm{T}$ cells and that this imprinting is essentially lifelong.

A head-to-head comparison of aP versus wP vaccination is not feasible in the US because the $\mathrm{wP}$ vaccine formulations are no longer licensed. Here, we compared $\mathrm{T}$ cell responses induced by original aP and $\mathrm{wP}$ priming (during the first years after birth), not immediately, but at the time of waning, more than 15 years after the original priming, and following the additional aP boosts (administered from middle to high school). To specifically address any differences, (i.e., magnitude, polarization, memory compartments, or capacity to respond to antigen stimulation), we measured responses ex vivo after aP booster to pertussis epitopes. A recent additional booster was taken as a "mimic" of how donors react when exposed to antigen in vivo. Importantly, these analyses revealed persistent differences at the level of $\mathrm{T}$ cell responses between individuals originally primed with aP versus wP.

\section{Results}

Differential polarization of pertussis-specific memory CD $4^{+}$T cells as a function of childhood vaccination. In a first series of cross-sectional experiments, we examined whether the difference in polarization between aP and wP donors was still detected in adulthood. These donors were originally primed with either aP or wP and were not, to the best of our knowledge, recently vaccinated, at least in the previous 4 years. The age and other general characteristics of this first donor cohort are summarized in Supplemental Table 1A (supplemental material available online with this article; https:// doi.org/10.1172/JCI121309DS1). By using a pertussis megapool stimulation together with activation-induced marker (AIM) and intracellular cytokine staining (ICS) assays, we were able to successfully detect and confirm, as previously reported (43), that Th polarization as a function of $\mathrm{WP}$ and aP childhood vaccination persists upon aP reimmunization in adolescents and adults (Figure 1A). Specifically, we measured IFN- $\gamma$, IL-4, and IL-17 responses in the 2 donor cohorts 1 to 3 months after aP boosting and calculated the number of total $\mathrm{CD} 4^{+} \mathrm{T}$ cells producing each cytokine. We 
A
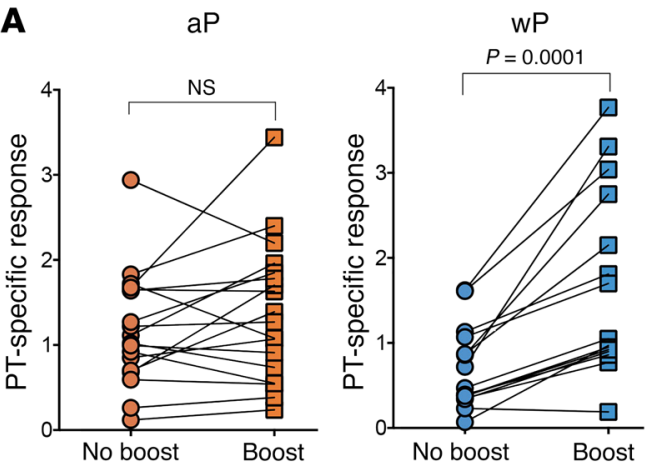

B

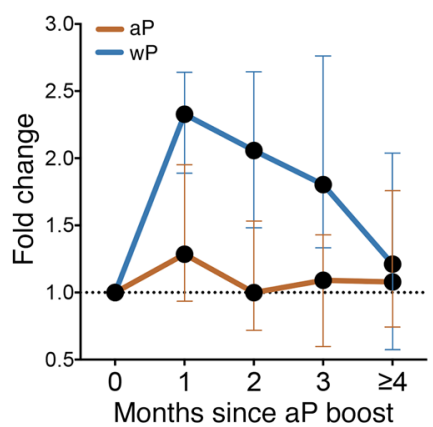

Figure 2. Original wP prime, but not aP prime, is associated with significantly higher $\mathrm{CD4}^{+} \mathrm{T}$ cells after aP boost. (A) Percentage of PT-specific CD4 ${ }^{+}$ memory T cells by AIM ${ }_{25}$ assay for donors originally primed with $w P$ or aP vaccine before or after the earliest boost time for each individual (0.5- to 2 -month range). Each dot represents a single donor determination followed longitudinally ( $n=18$ for aP and $n=15$ for WP cohorts). Wilcoxon's paired $t$ test. (B and C) Longitudinal kinetics of PT-specific CD4 ${ }^{+} T$ cell responses after boost represented as fold increase of the percentage of $\mathrm{AlM}_{25}{ }^{+}$cells to nonboost responses for aP- or WP-primed cohorts. Data are expressed as median \pm the interquartile range for each cohort. B, $n=18$ for $\mathrm{aP}$ and $n=17$ for $\mathrm{wP} ; \mathbf{C}, n=12$ for $\mathrm{aP}$ and $n=12$ for WP. (D) PT-specific CD4 ${ }^{+} T$ cell responses after boost represented as function of age for $\mathrm{aP}$ or WP cohorts. Each data point represents the fold increase to nonboost response from each donor ( $n=18$ for $\mathrm{aP}$ and $n=15$ for WP cohorts). The best fit of each data set is represented by linear regression lines (black).

observed a marked polarization toward IL-4-secreting cells in the aP-vaccinated cohort and IFN- $\gamma$ and IL-17 in the wP-vaccinated cohort. The separate determination of reactivity of pertussis epitopes derived from different antigens is of interest, but was not performed, given the limited amount of cells available for analysis in several of the samples and that the separate testing would have required a 4-fold higher number of cells. As expected, no difference in polarization of responses between the aP and wP cohorts was noted in the case of response to a megapool of epitopes derived from $\mathrm{CMV}$ and $\mathrm{EBV}$, ubiquitous pathogens not included in the $\mathrm{aP}$ or $\mathrm{wP}$ vaccines (Figure $1 \mathrm{~B}$ ).

Overall, these data highlight a persistent polarization of $\mathrm{T}$ cell responses in adulthood decades after priming and despite continued aP boosting of both cohorts (from 1996 onward as part of the recommend immunization schedule). The much stronger IL-17 polarization was reported as being associated with protection and $\mathrm{wP}$ vaccination in mouse and baboon models, but had not been shown for humans $(15,26,27,44-46)$.

Original wP prime, but not aP prime, is associated with higher number of pertussis-specific CD4 ${ }^{+} \mathrm{T}$ cells after aP boost. Further studies focused on longitudinal analysis of $\mathrm{T}$ cell responses to aP booster in adolescents and adults originally vaccinated with either aP or wP. Specifically, we compared responses in 18- to 19-year-olds originally primed with aP to those of older individuals originally primed with wP (Supplemental Table 1B). Ex vivo T cell responses to pertussis epitopes employing the $\mathrm{AIM}_{25}$ assay $\left(\mathrm{CD} 25^{+} \mathrm{OX} 4 \mathrm{O}^{+}\right)$ gating strategy were measured at baseline and 0.5 to 2 months after aP booster (Supplemental Figure 1). The results in Figure 2A show that original wP prime, but not aP prime, was associated with higher ex vivo $\mathrm{CD}^{+} \mathrm{T}$ cell responses after aP boost. Overall, for donors originally vaccinated 18 years (or more) earlier with wP, ex vivo responses were boosted by approximately 2.5 -fold. In the case of the donors vaccinated with aP, no significant booster effect was noted at the level of $\mathrm{T}$ cell responses.

The responses of these donors were further analyzed over a 6-month period. This analysis demonstrated that the apparent lack of effective booster effect was not associated with differential kinetics of the responses (Figure 2B). In both cases, the booster effect already peaked at the 1-month time point and waned afterwards (but was significant only for wP donors). These data could not determine whether the peak booster effect occurs before the 1-month time point so that the aP cohort might still be associated with a significant boost, but simply of a brisker and more transient nature. To address this issue, we recruited a third cohort of donors, also originally aP or wP primed (Supplemental Table $1 C$ ). In this cohort, responses were followed at days 1, 3, 7, 14, 30, and 60/120 after boost. The results shown in Figure $2 \mathrm{C}$ indicate that the peak booster effect was indeed reached at the 1-week point for the wP donors and that, regardless, no significant boost was detected in the donors originally primed with aP.

Finally, we ruled out that the differences observed might be due to differences in age between the 2 cohorts, since the response in terms of booster effect tended to be inversely correlated with age in the wP cohort (opposite trend) (Figure 2D). It would be of interest to investigate in future studies whether the number of boosters or the timing of the boosters in relationship to the most recent booster makes a difference in the responses, since clinical studies indicate that the more boosters that are given, particularly in adolescence, the shorter the duration of protection.

Memory subset composition of pertussis-specific $T$ cells and their molecular markers as a function of aP versus $w P$ priming. To further characterize the responses, we analyzed the expression of 
A

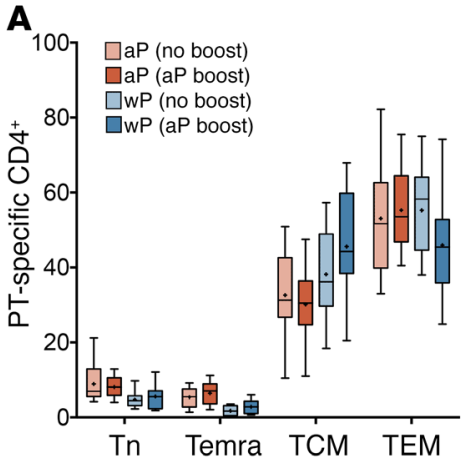

C

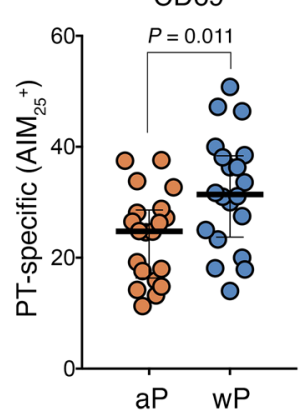

Figure 3. Memory subset composition of PT-specific responses. (A) Percentage of PT-specific CD4 ${ }^{+} \mathrm{T}$ cell subsets followed longitudinally (naive T cells [Tn]: CD45RA+CCR7+; effector memory RA T cells [Temra]: CD45RA+CCR7-; TCM: CD45RA-CCR7+; and TEM: (D45RA-CCR7-) gated in $\mathrm{AIM}_{25}{ }^{+}$cells. Asterisks indicate median. Minimum and maximum error bars are shown (aP boost: 0.5 - to 2-month range; $n=16$ for aP and $n=14$ for WP cohorts). (B) Longitudinal kinetics of PT-specific CD4 ${ }^{+}$responses from TCM (left panel) or TEM (right panel) subsets after aP boost. Data are expressed as median \pm the interquartile range for each cohort $(n=18$ for aP and $n=17$ for wP in both panels). (C) Expression of CD69 in aP versus wP cohorts as the percentage of $\mathrm{AIM}_{25}{ }^{+}$cells after aP boost (1- to 3-month range). Differences between cohorts analyzed via 2-tailed Mann-Whitney $U$ test. Each data point represents a single donor determination. $n=20$ for each cohort.
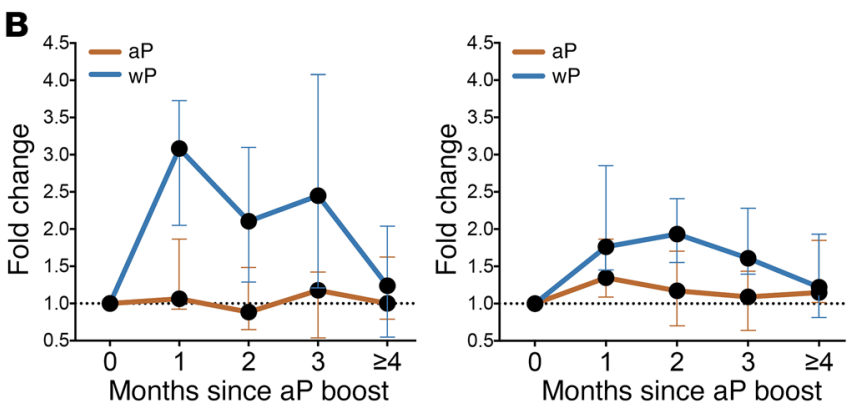

CD45RA and CCR7 on the responding T cells. As expected, the response in both aP-primed and wP-primed donors, either before or after the aP boost, was mediated by memory $\mathrm{T}$ cells. A trend existed toward higher $\mathrm{T}$ central memory (TCM) composition in the case of the wP-primed donors, especially after boost (Figure $3 \mathrm{~A})$. Further analysis demonstrated that, indeed, the response to the boost observed in the case of the wP cohort was mediated by both T effector memory (TEM) and TCM, but was more prominent in the case of the TCM subset (Figure 3B).

We reasoned that the differential responsiveness to the aP booster might be associated with differential expression of $\mathrm{T}$ cell markers commonly associated with $\mathrm{T}$ cell activation, apoptosis, and exhaustion. To address this possibility, AIM-responsive $\mathrm{T}$ cells were examined for the expression of the CD69, CD71, CD27, and CD28 activation markers. In terms of apoptosis markers, we utilized Bcl-2 and FasL. Finally, in terms of exhaustion and anergic markers, we utilized PD-1, PD-L1, Tim3, CTLA-4, KLRG1, and BTLA. With the exception of CD69 (Figure 3C and data not shown), there were no significant differences in the responding $\mathrm{T}$ cells of the aP and wP cohorts at the level of activation, exhaustion, and apoptotic pathways.

Original $w P$ or aP prime is associated with equivalent increases of IgG antibody titers and plasmablasts, but not IgG4, after aP boost. Antibody titers to the 4 pertussis antigens, pertussis toxin (PT), pertactin (PRN), filamentous hemagglutinin (FHA), and fimbriae types 2 and 3 (FIM2/3), were measured at baseline and 1 to 3 months after aP booster and represented as overall pertussis response (individual antibody responses to each pertussis antigen are shown in Supplemental Figure 2; these follow similar trends). As shown in Figure 4, A and B, total pertussis antibody titers from both donors originally primed with $\mathrm{wP}$ or aP vaccine were generally similar before boost, were equally elevated after an aP boost, and followed a similar kinetic pertussis antibody profile. Antibodies to non-aP antigens (i.e., adenylate cyclase toxin [ACT] or mea-

sles) did not significantly increase after aP immunization (data not shown). Levels of pertussis-specific IgG-secreting plasmablasts were also equivalent after an aP boost (Figure 4C). We then evaluated whether the pertussis-specific IgG subclass distribution followed a trend similar to that of Th polarization (Figure 1) after an aP boost by measuring IgG1 and IgG4 pertussis-specific Abs as an indicator for a Th1 or Th2 response, respectively. Both wP- and aP-primed individuals elicited increased pertussis-specific IgG1, but not IgG4, responses following aP immunization (Figure 4, D and E). When assessing relative aP-specific IgG4 changes after immunization, individuals in the aP cohort had significantly elevated aP-specific IgG4 antibodies compared with $\mathrm{WP}$ individuals (Figure 4F; 5.1 vs. 0.7 median fold change between time before and time after aP boost, respectively).

The data above demonstrate that, while total IgG antibody responses were boosted in both aP and wP cohorts and followed IgG subclass distribution corresponding to Th polarization, the $\mathrm{T}$ cell response was not effectively boosted in the originally primed aP donors (Figure 2). This suggests that waning immunity is a $\mathrm{T}$ cell-specific and not B cell-specific defect.

Transcriptomic profiles of pertussis-specific T cells from aP-versus $w P$-vaccinated donors. To investigate the nature of the differences between aP and wP original priming, we determined transcriptomic profiles in $\mathrm{T}$ cells from wP- and aP-primed donors in response to pertussis megapool stimulation 2 to 3 months after Tdap boost vaccination. These donors were randomly selected among donors for whom sufficient cell numbers were available. AIM-reactive $T$ cells were sorted as a function of memory subsets. As a first step, we ran an unbiased principal component analysis (PCA) (Figure 5A). In the case of pertussis-reactive $\mathrm{T}$ cells, wP-TEM cells are clearly separate from aP-TEM cells. Next, we determined the number of genes differentially expressed between aP-TEM and wP-TEM cells that responded to the pertussis megapool, which identified a total of 13 genes with a stringent adjusted $P$ value of less than 0.05 (Figure 5B).

IL-9 was one notable gene upregulated in the aP-primed donors. This gene is implicated in pleiotropic activities, such as regulation of $\mathrm{T}$ cell immune responses in allergies and asthma, as well as antitumor and antiworm immunity (47-52). The ANAPC2 and WDR4 genes were downregulated in wP-primed donors. ANAPC2 is part of the anaphase-promoting complex that modulates the progression through the different phases of the cell cycle $(53,54)$. WDR4 (AIP1) is also implicated in cell-cycle progression 

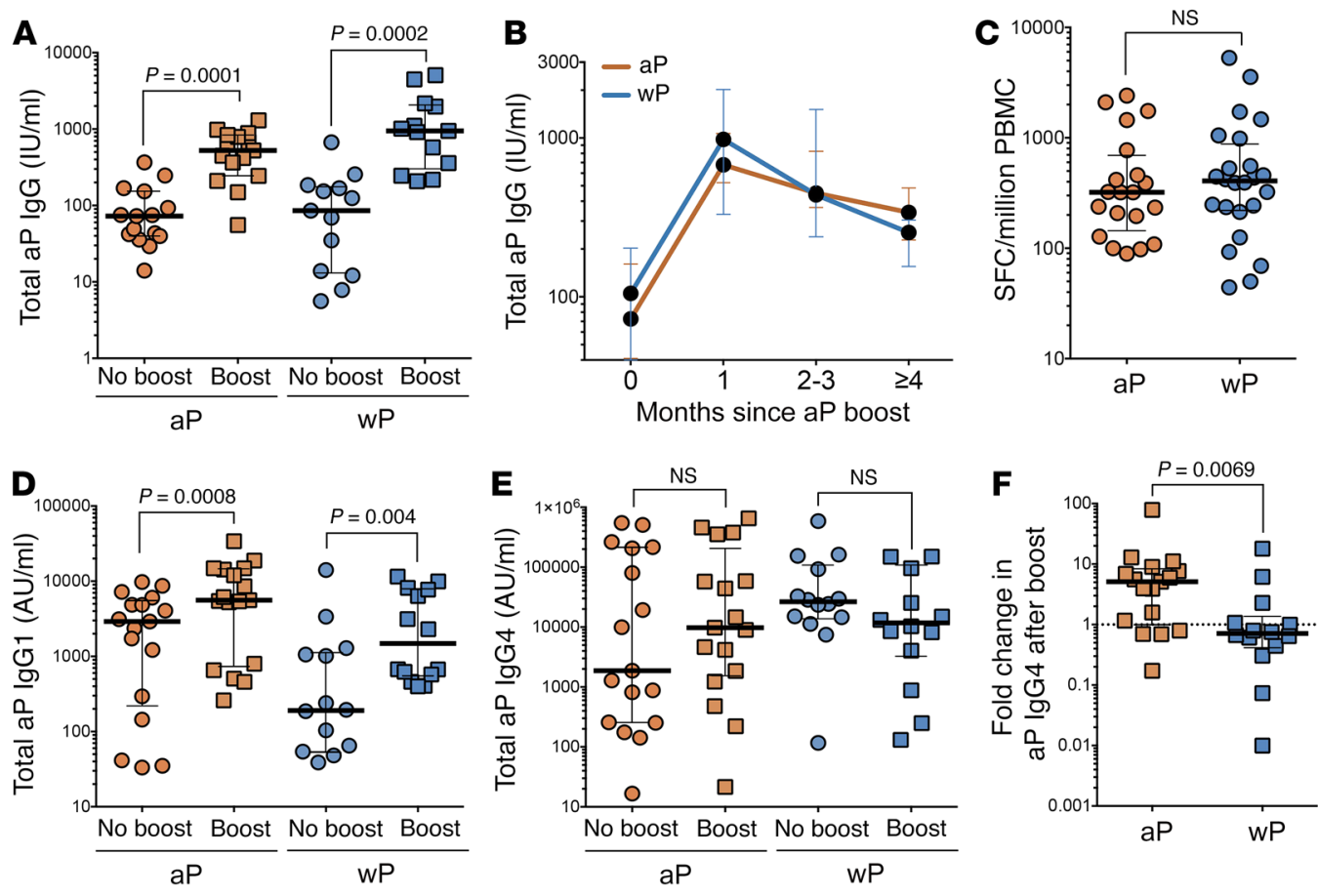

Figure 4. wP- and aP-primed donors elicit elevated pertussis-specific IgG and IgG1, but not IgG4, titers after aP boost. (A) Sum of IgG antibody titers for aP antigens (FHA, PT, and PRN) in respective cohorts. Response before and after vaccine analyzed via Wilcoxon's paired $t$ test. (B) Kinetic representation of antibody titers. (C) Analysis of plasmablast memory B cell responses at day 7 after Tdap boost. Data represent overall Ab secretion against aP antigens as measured by ELISPOT. (D) Sum of pertussis (FHA, PT, PRN, and FIM2/3) IgG1 and (E) IgG4 levels as representative responses to aP for each cohort. Response before and after vaccine analyzed via Wilcoxon's paired $t$ test. (F) Fold change in aP IgG4 levels after aP boost for each cohort. Data represent average fold change of all aP antigens (PT, FHA, PRN, and FIM2/3) for each individual. Comparison between aP and wP fold change analyzed via Mann-Whitney unpaired $t$ test. For all panels, data are expressed as median \pm the interquartile range for each cohort and each data point represents a single donor. $n=19$ for $\mathrm{aP}$ and $n=14$ for wP cohorts except for $\mathbf{C}$, in which $n=20$ for aP and $n=24$ for wP.

and cell migration $(55,56)$. Also notable is the differential expression of TGIF2, which encodes a protein-repressing transcription by recruiting histone deacetylases to TGF- $\beta$-responsive genes (57, 58). These results suggest that aP versus $\mathrm{wP}$ priming is associated with alterations in specific $\mathrm{T}$ cell subsets (as suggested by the differential polarization) and in cell proliferation (consistent with lack of in vivo boost in aP-primed donors).

Enrichment and network analysis revealed 2 main alterations linked to differential priming. Further analysis revealed that the IL-5, IL-13, and TGF- $\beta$ genes displayed a higher expression level for the aP cohort (Figure 5C). In addition, for genes encoding proteins differentially expressed in the previous experiments, similar trends at the transcriptomic level were found (Figure 5D). Conversely, the IL- 9 difference originally detected by gene expression was also confirmed at the protein level (Figure 5D). We next analyzed the 500 genes that showed the largest difference in expression between aP and wP cohorts, using the Gene Set Enrichment Analysis (GSEA) algorithm (http://software.broadinstitute.org/ gsea/index.jsp). GSEA is a computational method that determines whether certain biological functions are significantly represented in the input group of genes. We found (Table 1) that 3 different gene categories were significantly enriched below the $10^{-4} \mathrm{FDR}$ threshold, the first two related to cell division (mitosis and cell cycle) and the third to immune system function genes. Next, the genes differentially expressed from 3 categories were subjected to Ingenuity Pathway Analysis (IPA) to obtain additional functional insights (Figure 6). We found that mitosis and cell-cycle progression genes that promote cell division were increased in wP samples (Figure 6A). In addition, IPA analysis for the immune system category (Table 1) identified IRF3 and IFN- $\beta$ as potential upstream regulators of IL-17 and IL-9 (Figure 6, B and C). Coexpression analysis also identified GFI-1 as the gene most highly correlated with IL-9 expression (data not shown). GFI-1 is of interest, as it suppresses Th17 differentiation (and also inducible Tregs). IL-4 induces GFI-1 expression in Th2 cells, while TGF- $\beta$ suppresses GFI-1 expression. Furthermore, the GFI-1 transcription factor is required to maintain the Th2 phenotype $(59,60)$.

Original wP priming is associated with higher proliferative capacity. Based on the transcriptomic findings, we hypothesized that the capacity of memory $\mathrm{T}$ cells to expand in response to antigenic stimulation might differ as a function of the original priming (aP versus $\mathrm{wP})$. Indeed, data from the literature highlighted higher proliferative capacities of aP-primed donors relative to wP-primed donors in 7-month-olds and 4-year-olds $(31,61)$, but equivalent capacity in 10-year-olds (62). We tested this hypothesis using proliferation assays in which cells were labeled with CFSE at a final concentration of $10 \mu \mathrm{M}$. Analysis of cells immediately following labeling indicated a labeling efficiency higher than $99 \%$. Rounds of cell division were determined by sequential halving of CFSE-fluorescence intensity. As expected, the proliferating cells were derived from memory compartments (not shown). In the next series of experiments, we addressed whether the originally aP-primed memory $\mathrm{T}$ 
A
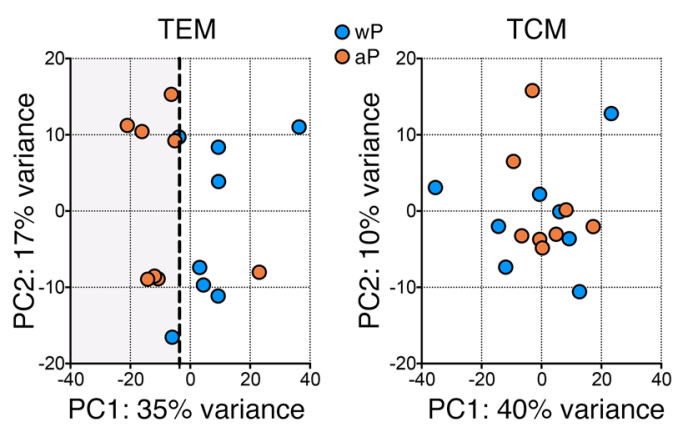

B

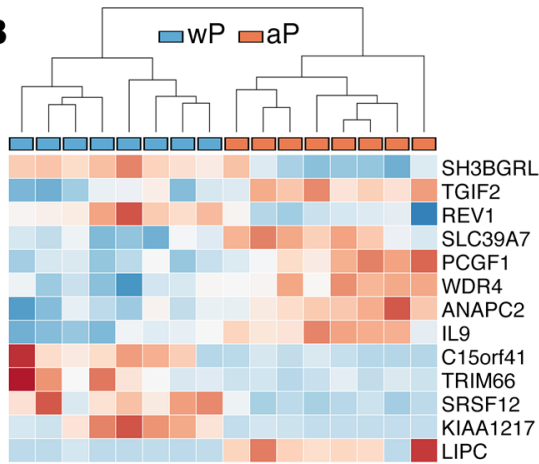

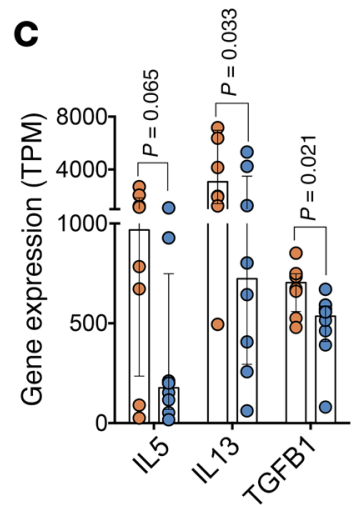

IL-9
D CD69

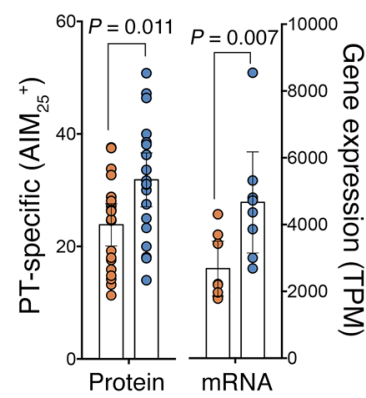

IL-4

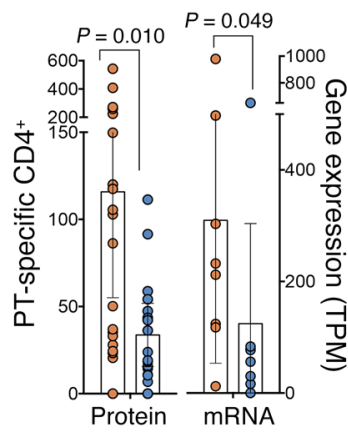

IL-17

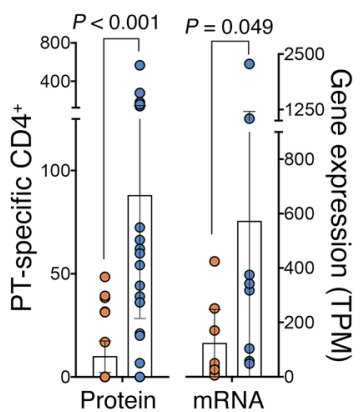

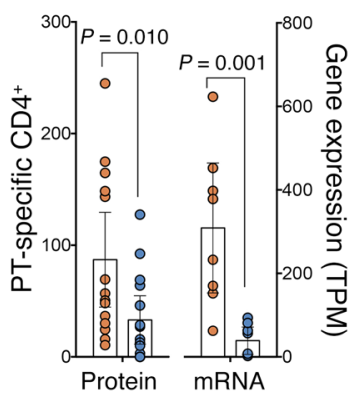

Figure 5. Comparison of gene expression profiles of PT-stimulated T cells for aP- and wP-vaccinated donors after boost. PT-specific CD4+ $T$ cells were isolated by AIM25 assay and sorted as a function of memory TEM and TCM subsets. RNA-seq was performed. (A) Unbiased PCA of TEM and TCM subsets from $\mathrm{aP}$ and $\mathrm{WP}$ donors based on the top 1,000 variable genes. Each data point represents a single donor. $n=8$ for each cohort. (B) TEM cells from aP and wP donors $(n=8)$ were clustered based on the 13 differentially expressed genes (adjusted $P<0.05)(\mathbf{C}$ and $\mathbf{D})$ Expression of indicated cytokines and CD69 at the mRNA ( $n=8$ for each cohort)or protein level. Protein data are represented as percentage of CD69 in AIM ${ }_{25}{ }^{+}$cells ( $n=20$ for each cohort) or the number of IL-4- and IL-17- ( $n=23$ for each cohort) or IL-9-secreting ( $n=15$ for each cohort) cells measured in ICS staining by pertussis-specific AIM 25 assay. mRNA data are represented as the number of transcripts per million (TPM) after RNA-seq normalization for the respective gene. Results are presented as median \pm interquartile range. All determinations were performed in recently boosted donors (1- to 3-month range) Each dot represents 1 donor from aP (orange) versus wP (blue). Differences analyzed via 2-tailed Mann-Whitney $U$ test.

cells that could experience waning of immunity were associated with lower proliferative capacity after Tdap boost vaccination. The results shown in Figure 7A show that this is indeed the case. In conclusion, these data validate, at the biological level, the hypothesis that the original $\mathrm{wP}$ priming generates a $\mathrm{T}$ cell response associated with long-lasting proliferative capacity, leading to the hypothesis that gradual loss of proliferative capacity might be associated with waning of pertussis-specific memory $\mathrm{T}$ cell responses. Further experiments suggested that these effects might, at least in part, be linked to a regulatory cell population, since no difference in aP versus $\mathrm{wP}$ donors was noted when purified $\mathrm{T}$ cell subpopulations were assayed, suggesting that a different population contained in the peripheral blood mononuclear cells (PBMCs) might be responsible for the effect (Figure 7B).

Some, but not all, alterations extend to TT-specific responses. The data presented above demonstrate several alterations in pertussis-specific responses as a function of the original aP versus $\mathrm{WP}$ priming and implicate some alterations possibly related to antigen-presenting cell (APC) function and upstream regulation of the $\mathrm{T}$ cell responses. In general, we also showed that the alterations detected did not extend to unrelated antigens such as CMV, EBV, or measles. The aP and wP vaccines, however, both contain TT. For this reason, we performed experiments to determine whether these alterations were limited to pertussis antigens or more generally applicable to other components of the vaccine, such as TT. Strikingly, our results showed that TT-specific $\mathrm{T}$ cell responses were significantly boosted in wP but not aP donors, but that total IgG antibody responses were significantly boosted in both cohorts (Figure $8, \mathrm{~A}^{-} \mathrm{C}$ ). Similar differences, albeit much less pronounced, were also detected in terms of Th response polarization (Figure 8D), and no differences 

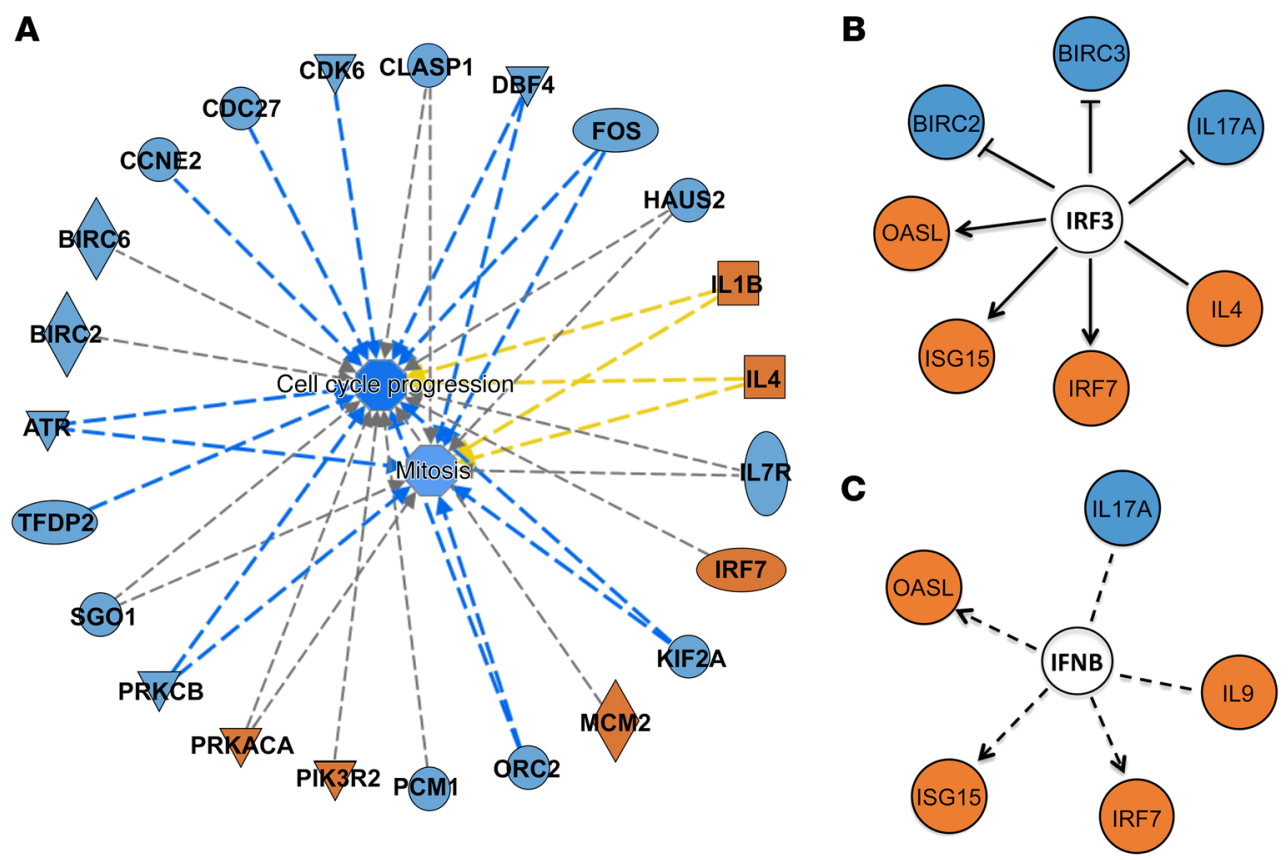

Figure 6. Modular transcriptomic and pathway analysis reveals alterations linked to differential priming.

(A) Network analysis for gene functions involved in mitosis and cell cycle progression. These functions were significantly enriched for the $\mathbf{5 0 0}$ genes with the highest value of fold change between aP and wP donors. Lines indicate relationships between genes and functions. Blue lines indicate activation effects, and gray lines indicate genes known to be involved in function, but with unknown effect. Orange and blue nodes indicate upregulated in $\mathrm{aP}$ and $\mathrm{wP}$, respectively. Yellow lines indicate that the relationships are inconsistent with the state of the node. (B) IRF3 and (C) IFNB were identified as upstream regulators. Solid and broken lines denote a direct or indirect effect, respectively. Line with an arrowhead indicates activation, while a flat end indicates inhibitory effect. few individuals predominantly in the aP cohort had PT antibody titers between 50 and $100 \mathrm{IU} /$ $\mathrm{ml}$ before their aP boost (Supplemental Figure 2), potentially indicating a recent $B$. pertussis exposure (64). Although beyond the scope of this study, it would be of interest to evaluate antibody and $\mathrm{T}$ cell polarization and function in the context of a natural boost (i.e., exposure to $B$. pertussis) in both aP- and wP-primed cohorts.

Furthermore, over approximately 15 years and repeated aP boosts, $\mathrm{T}$ cells originally primed with aP become associated with diminished capacity to respond to a boost in vivo. Alterations in proliferative capacity were validated in CFSE proliferation assays, and cell fractionation experiments suggest a potential regulatory effect. These observations are consistent with the known capacity of TGF- $\beta$ to either be suppressive or to inhibit $\mathrm{T}$ cell proliferation (65). This report adds to a previous report from our group (43) that defined the epitopes were determined in TT-specific IgG subclass distribution (Supplemental Figure 3). However, at the gene expression level, poor separation in the PCA was observed for TT responses (Supplemental Figure 4) and the genes differentially expressed in pertussis were not so differentially expressed in the case of TT responses. Finally, a similar trend in terms of proliferation of TT-specific $\mathrm{T}$ cells was noted between the aP and wP cohorts (Figure 8E), but this trend was not significant. These results suggest that the alterations seen in the case of pertussis responses also extend, but only in part, to TT-specific responses.

\section{Discussion}

Our results demonstrate that priming in the first few months after birth with the aP or wP vaccines induces different $\mathrm{T}$ cell phenotypes. Ex vivo analysis of pertussis responses revealed that, while original wP and aP prime are both initially capable of generating protective immunity, intrinsic differences in phenotype persist/ evolve for more than 15 years. Pertussis responses remain polarized as a function of the original priming vaccine (which correlates with another report, ref. 35), but not toward CMV/EBV. Polarization was associated with IL-4, IL-9, and TGF- $\beta$ in aP-primed and IFN- $\gamma$ and IL-17 in wP-primed donors. We also observed that pertussis-specific IgG4 antibodies were significantly elevated in aP compared with wP individuals (which correlates with other reports, refs. 21, 63); this further supports the finding that pertussis-IgG subclass distribution is dictated based on the distinct Th polarization mediated by initial vaccine type. Interestingly, a recognized in aP and $\mathrm{wP}$ vaccination and reported a long-lasting polarization. In that study, only cross-sectional cohorts were probed, while the present study shows longitudinal analyses, including ex vivo analysis of $\mathrm{T}$ cell reactivity, proliferation assays, and transcriptomic profiling, to investigate the mechanisms of the differences involved in priming with the 2 different vaccines. The study design and major findings are highlighted in Figure 9.

As a result of the work described herein, we detected a key intrinsic difference in responses, associated with differential polarization. Besides the previous documented differential Th1 versus Th2 polarization (43), we show a differential IL-9/IL-17 polarization in adulthood after aP versus wP childhood vaccination. Indeed, stronger IL-17 polarization from $\mathrm{wP}$ vaccination has been reported to be associated with higher protection in baboon models $(15,26,27,44)$ and to be pivotal in the mediation of adaptive immunity by tissue-resident memory $\mathrm{T}$ cells after natural infection in mice $(45,66)$. Although IL-17 has been detected in supernatants of PBMCs stimulated with pertussis antigens (67, 68), to the best of our knowledge, this is the first time that $\mathrm{CD}^{+}$ T cells secreting both IL-9 and IL-17 have been shown to be associated with pertussis-specific responses after wP or aP vaccination regimens in humans.

Based on reports in the literature, TGF- $\beta$ can work as a masentiation from naive $\mathrm{T}$ cells in response to the presence of other cytokines $(70,71)$. Moreover, our network analysis suggests that IFN- $\beta$ is an upstream regulator of both IL- 9 and IL-17. It is thus ter-switch regulator (69) and promotes Th9, Th17, or Treg differ- 
A

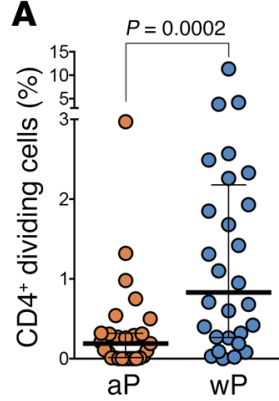

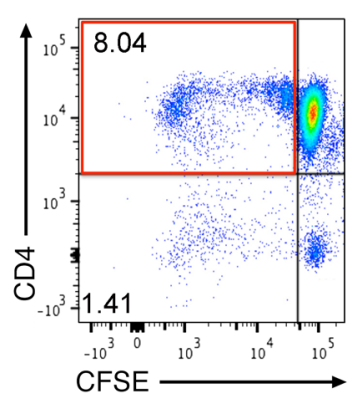

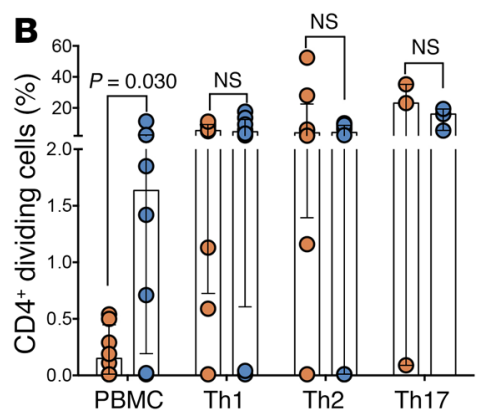

Figure 7. Original wP priming is associated with higher proliferative capacity. The proliferative capacity of PT-specific cells was assessed by CFSE assay after 6 days of stimulation. (A) Percentage of dividing $\mathrm{CD}^{+}{ }^{+} \mathrm{T}$ cells by CFSE quenching in both cohorts. Results are presented as median \pm interquartile range for each cohort, and each data point represents a single recently boosted donor (1- to 3-month range; $n=27$ for aP and $n=28$ for wP cohorts). Dot plot shows double labeling of CD4 versus CFSE for a representative WP-primed donor. (B) Percentage of dividing CD4 ${ }^{+} \mathrm{T}$ cells in purified T cell subsets from aP (red) versus wP (blue). Differences between cohorts analyzed via 2-tailed Mann-Whitney $U$ test. Donor samples obtained from leukapheresis after Tdap boost (1- to 12-month range). $n=8$ donors.

$\mathrm{T}$ cell subpopulation or a regulatory cell of different nature), since no difference in aP versus wP donors was noted when purified $\mathrm{T}$ cell subpopulations were assayed. This suggests that a different population contained in the PBMC is responsible for the effect. It is possible that the effect is mediated by suppressive activity of classic Tregs (i.e., IL-10, TGF- $\beta$, and CTLA-4) or IFN- $\beta$-secreting APCs, although this inference is not strongly supported by the data available and will have to be addressed in further experiments. We consider it likely that any regulatory effect is mediated by antigen-specific T cells, such as Th9 (this cell subset was not yet purified in the experiment shown in Figure 7), since it is unlikely that non-antigen-specific $\mathrm{T}$ cells would develop over the course of over 10 years. Alternatively, a different interprepossible that the IL-17/IL-9 polarization in pertussis responses results from differences in the priming and expansion of pertussis-specific T cells related to the production of TGF- $\beta$ and the presence of mediators such as IL- 1 and IFN- $\beta$.

Specifically, we speculate that priming with the aPvaccine results in production of IL- 1 and IFN- $\beta$, while priming with wP results in lower levels of these mediators; we hypothesize that this will in turn modulate the effect and magnitude of TGF- $\beta$ production, which, together with IL-9 production, may block Th17 differentiation in aP donors and eventually induce Tregs that inhibit proliferation.

The functional data described above were also confirmed by transcriptomic analysis of $\mathrm{T}$ cells derived from the 2 cohorts of donors originally primed with aP or wP. This analysis identified additional potential candidates for further analyses, such as TGIF-2, a gene that encodes a protein repressing transcription of TGF- $\beta$-responsive genes $(57,58)$, and the transcriptional repressor GFI-1, whose gene expression has the highest correlation with IL-9 among all the genes in our set of data. GFI-1 has been shown to play pivotal roles in both Th2 cell expansion and negative regulation of Th17 differentiation $(59,60)$.

The other striking finding revealed by our study is that donors originally primed with aP have decreased capacity to respond to a booster immunization in vivo and diminished proliferative capacity in vitro. Differences in T cell-proliferative response have already been shown in children and depict higher proliferative responses for aP-vaccinated as compared with wP-vaccinated individuals just after the 3 initial vaccinations or at the end of the primary series (5 vaccinations) $(31,61)$. However, and in stark contrast, our results and those of others (62) suggest that gradual aP loss of proliferative capacity occurs with increasing age and might contribute to impaired pertussis-specific memory $\mathrm{T}$ cell responses to boost vaccine and overall waning of immunity. The ANAPC2 and WDR4 genes differentially regulated in wP- versus aP-vaccinated children are involved in cell-cycle transitions $(72,73)$ and in cell proliferation and migration $(55,56)$, respectively.

Our data suggest that differential proliferative profiles might be linked to a regulatory cell population (either a pertussis-specific tation of the results suggests that key intrinsic differences might exist at the level of memory $\mathrm{T}$ cells with differential susceptibility to being suppressed by regulatory cells.

Another scenario is that the differences at the level of $\mathrm{T}$ cell phenotype might lead to different patterns of activation at the APC level and, as a feedback loop, lead to a regulatory influence on $\mathrm{T}$ cell responses. Indeed, it is well recognized that dendritic cells enhance antigen presentation and elicit polyvalent immune responses in vaccination against yellow fever $(74,75)$, influenza $(76,77)$, or tuberculosis $(78)$. In this context, pertussis antigens are also known to have adjuvant activity and activate APC. For this reason, in future studies, it will be of interest to determine whether APC alterations generally affect responses to other components of the vaccines, such as TT.

A feedback loop involving APC "licensing" is an attractive possibility, based on the known adjuvant activity of wP and the fact that certain features of differential pertussis responses appear to "spill over" to TT responses (since TT is also contained in the $\mathrm{WP}$ or aP vaccines). In agreement, we have shown previously that TT responses remained polarized despite the original priming having occurred decades before (79), suggesting enactment of specific molecular programs in memory $\mathrm{T}$ cells. More specifically, we hypothesize that the differentially polarized $\mathrm{T}$ cells might impart, upon antigen encounter and stimulation, differential signaling to APC, resulting in the generation of a "suppressive" or "stimulatory" APC function for the IL-9- versus IL-17-producing T cells, respectively.

In conclusion, our data suggest that long-lasting effects and differences exist between adults originally vaccinated with aP versus wP. In this context, it must be noted that adverse reactions to the original $\mathrm{wP}$ vaccine, although already substantial from the first administration, increased with each subsequent dose in the primary series and specifically upon booster doses (80-82). Also, albeit globally less reactogenic, the aP vaccine's elevated production costs limit its worldwide use, especially in developing countries (83). Thus, a vaccination regimen in which only the initial round of vaccination would be administered utilizing the wP vaccine and in which this would be followed by aP boosters could be 
A
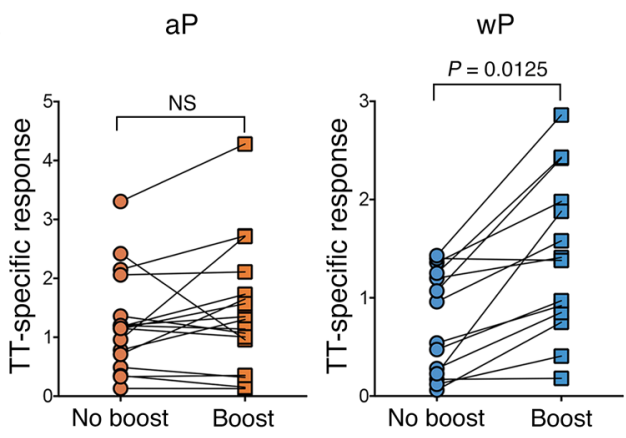

C

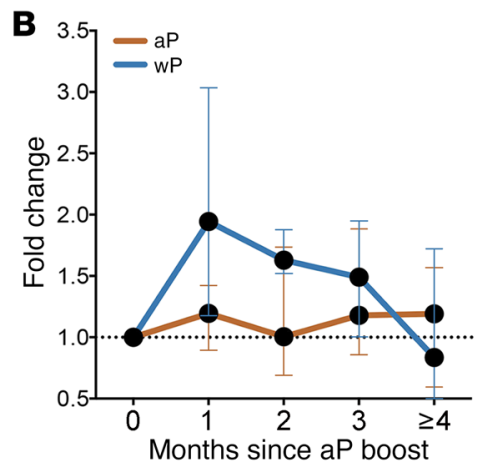

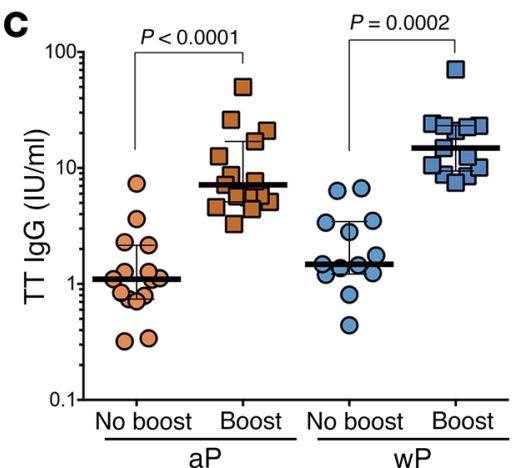

E

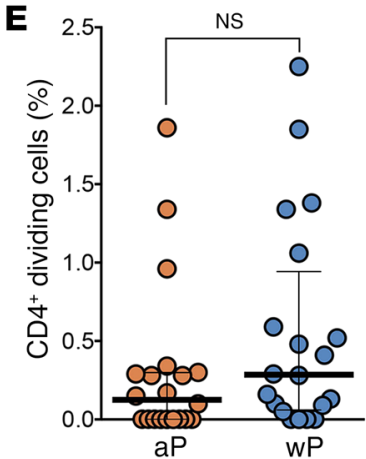

D

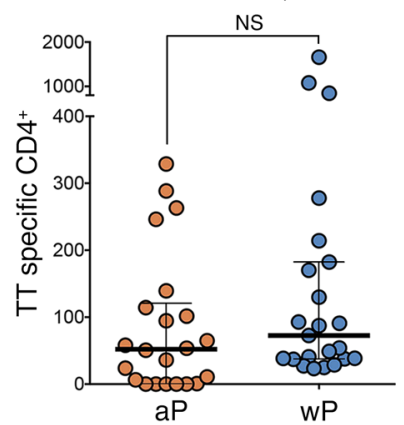

IL-4

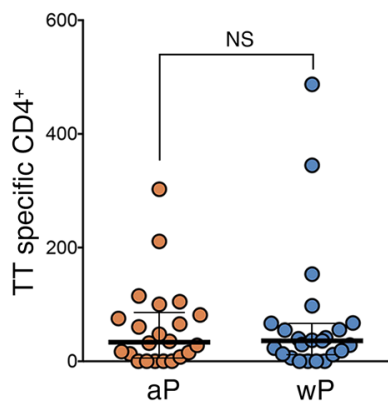

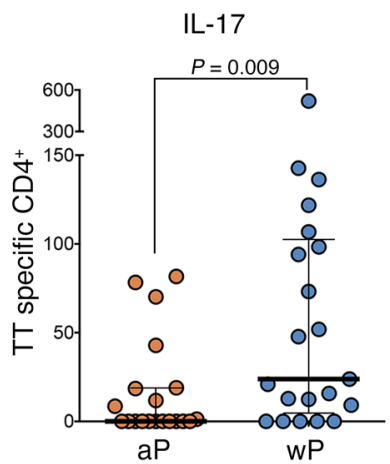

Figure 8. Some, but not all, alterations extend to TT-specific responses. (A) Percentage of TT-specific CD4 ${ }^{+} \mathrm{T}_{\text {cell }}$ subsets gated in AIM ${ }_{25}{ }^{+}$cells before or following boost. Each dot represents 1 donor followed longitudinally ( $n=17$ for aP and $n=14$ for WP cohorts). Wilcoxon's paired $t$ test. (B) Longitudinal kinetics of PT-specific CD4+ $\mathrm{T}$ cell responses after boost represented as fold increase of the percentage of $\mathrm{AIM}_{25}{ }^{+}$cells to nonboost responses for aP- or wP-primed cohorts. Data are expressed as median \pm the interquartile range for each cohort ( $n=18$ for aP and $n=17$ for wP cohorts). (C). Ab titers for TT toxoid antigen in respective cohorts ( $n=19$ for aP and $n=14$ for WP cohorts). Response before and after boost vaccine analyzed via Wilcoxon's paired $t$ test. (D) Total TT-specific CD4+ T cell number response after AIM $_{25}$ assay to each indicated cytokine. Each dot represents 1 donor ( $n=23$ for each cohort). $P$ value is shown as statistically significant by 2-tailed Mann-Whitney $U$ test. (E) Percentage of TT-specific CD4+ T cells after 6 days of CFSE assay. Results are presented as median \pm interquartile range ( $n=20$ for each cohort).

considered. Alternatively, the addition of a Th1-polarizing adjuvant to the existing aP vaccine may be a way forward. Our data clearly illustrate that at least some of the immunological features imparted by the $\mathrm{WP}$ prime will be maintained despite middle and high school booster vaccinations with aP. This in turn parallels the epidemiologic observations that individuals originally vaccinated with $\mathrm{wP}$ versus aP have more durable protection from disease, regardless of aP boosters during adolescence $(1,15,83)$.

\section{Methods}

Study subjects. We recruited 114 healthy adults from San Diego, California, USA (Supplemental Table 1). Clinical medical history from all participants was collected and evaluated. Clinical data for each patient were collected by multiple approaches. Whenever possible, vaccination records were collected from study participants or parents or custodian as appropriate. For some donors, the original clinical vaccine record was not available or was incomplete, in which case, information was collected by the clinical coordinators through questionnaires, recording dates and numbers of vaccination, including the information that no boost was administered at least in the previous 4 years prior to this study. All donors were from the San Diego area and, to the best of our knowledge, followed the recommended vaccination regimen (which is also necessary for enrollment in the California school system), which entails 5 DTaP doses for children under 7 years old (3 doses at 2, 4, and 6 months and then 2 doses between 15-18 months and 4-6 years) and a Tdap booster immunization at 11 to 12 years and then every 10 years. Individuals who had been diagnosed with B. pertussis infection at any given time in their lives were excluded. Other exclusion criteria were pregnancy at the start of the study, present severe disease or medical treatment that might interfere with study results, any vaccination in the last month and/or antibiotic use or fever in the last month $\left(>100.4^{\circ} \mathrm{F}, 38^{\circ} \mathrm{C}\right)$. In all groups, male and female subjects were included equally. From the remaining participants, a subset of these donors, originally vaccinated with either DTwP or DTaP in infancy, received a booster vaccination with Tdap and donated blood $1,2,3$, or 4 or more months after the boost. Alternatively, in a second subset of aP- or wP-primed patients, blood was collected at days 1, 3, 7, 14, 30, and 60/120 after Tdap boost.

Booster vaccination. For booster vaccinations, participants received a booster vaccine (Adacel) with TT, reduced diphtheria toxoid, and aP vaccine adsorbed (Tdap). Each dose of Adacel vaccine ( 0.5 $\mathrm{ml}$ ) contained the following active ingredients: $2.5 \mu \mathrm{g}$ detoxified PT, 5 $\mu \mathrm{g}$ FHA, $3 \mu \mathrm{g}$ PRN, $5 \mu \mathrm{g}$ FIM, 5 Lf TT, and 2 Lf diphtheria toxoid (DT). Other ingredients included $1.5 \mathrm{mg}$ aluminum phosphate $(0.33 \mathrm{mg}$ of aluminium) as the adjuvant besides residual formaldehyde, glutaraldehyde, and phenoxyethanol.

Peptides. Peptides were derived from B. pertussis antigens included in the aP vaccines (FHA, FIM2/3, PRN, and PT) from the Tohama I 


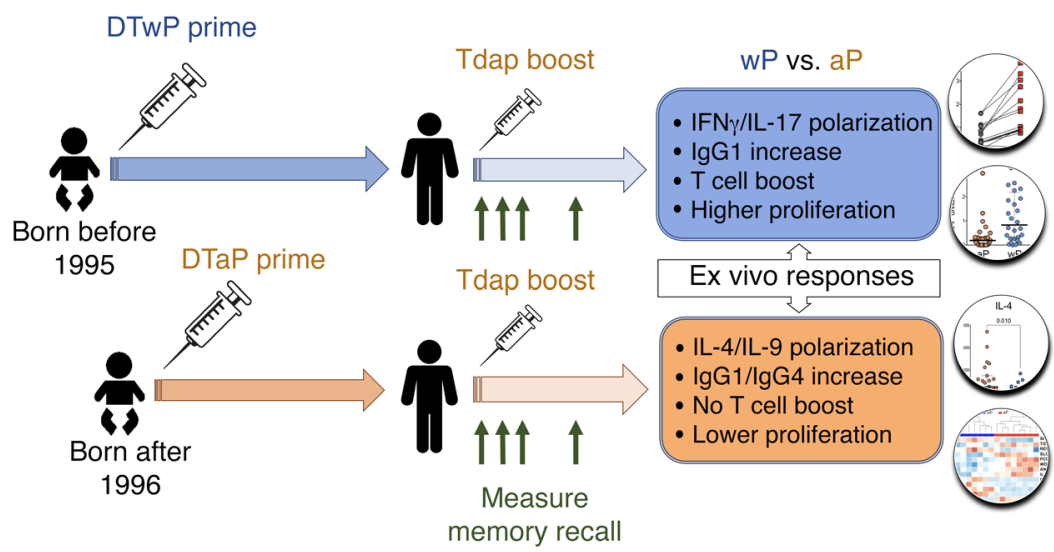

Figure 9. Experimental design and major findings of the study. Primary vaccination with 5 doses ( 3 doses at 2, 4, and 6 months and then 2 doses between 15 and 18 months and 4 and 6 years) of whole-cell (DTwP) or acellular vaccine (DTaP) occurred during the first years of life. A contemporary acellular vaccine (Tdap) boost was administered more than 15 years later and memory recall response measured using ex vivo analysis of $\mathrm{T}$ cell or B cell reactivity, proliferation assays, and transcriptomic profiling. The major immunological differences for each cohort (wP vs. aP) are depicted in the boxes (blue and orange, respectively). and 18323 strains. Of 785 peptides, 16 -mers overlapping by 8 residues, the top epitopes recognized by more than $5 \%$ of donors corresponding to 132 peptides were chosen (43). Epitopes from TT were also selected as recently described (79). A total of 122 previously defined epitopes of $\mathrm{EBV} / \mathrm{CMV}$ were also used as a control for antigens not contained in the vaccine (84). Peptides were synthesized as crude material on a small (1 $\mathrm{mg}$ ) scale by Synthetic Biomolecules. Individual peptides were resuspended in DMSO, and equal amounts of each peptide were pooled to construct peptide pools. To minimize DMSO concentrations in the assays, pools of more than 100 peptides (megapools) were generated as described (84). For this procedure, each individual lyophilized peptide was dissolved in $100 \% \mathrm{DMSO}$ at $20 \mathrm{mg} / \mathrm{ml}$ (for $0.5 \mathrm{mg}$ of peptide, this corresponds to a volume of $50 \mu \mathrm{l})$. Then equal amounts of each peptide were mixed well. For 100 peptides, this corresponsed to $50 \times 100=5 \mathrm{ml}$; the total peptide concentration was still $20 \mathrm{mg} /$ $\mathrm{ml}$, but the concentration of each peptide was now $0.2 \mathrm{mg} / \mathrm{ml}$, all in $100 \%$ DMSO. The resulting $5 \mathrm{ml}$ were then lyophilized, adding water if required. The resulting "lyocake," or megapool, was next carefully dissolved in the smallest amount of DMSO feasible. Usually a megapool easily dissolves in $100 \mu \mathrm{l}$ of $100 \%$ DMSO. This corresponds to $10 \mathrm{mg} / \mathrm{ml}$ of each peptide in $100 \% \mathrm{DMSO}$, and a final concentration of $2.5 \mu \mathrm{l} / \mathrm{ml}$ in an assay corresponds to $0.05 \%$ DMSO. This approach has been used to develop megapools specific for Timothy grass, tuberculosis, dengue virus (DENV), pertussis, and tetanus (43, 79, 85-87). All the peptides used in this study are listed in Supplemental Table 2.

PBMC isolation. PBMCs were isolated from whole blood or leukapheresis by density gradient centrifugation according to the manufacturer's instructions (Ficoll-Paque PLUS, Amersham Biosciences), as previously described (88). Cells were cryopreserved in liquid nitrogen suspended in FBS containing 10\% (vol/vol) DMSO.

Multiplexed luminex immunoassays. Antigen-specific antibody responses were measured through a modified multiplexed Luminex assay (89). Pertussis and tetanus proteins (pertussis toxin mutant, PT, PRN, FIM2/3, ACT, and TT from List Biological Laboratory and FHA from Sigma-Aldrich), inactivated Rubeola antigen as an internal vaccine control (Edmonston strain from Meridian Life Science Inc.), and an irrelevant protein (PD1) as an internal negative control were coupled to distinct fluorescent-barcoded MagPlex microspheres (Luminex Corp.). Serum from each individual, WHO B. pertussis human serum reference standard (NIBSC 06/140), or TT antibody standards were mixed with an equimolar mixture of each conjugated microsphere. The microspheres were then washed with a PBS-Tween
20 buffer to release nonspecific antibodies, and bound antibodies were detected via anti-human IgG phycoerythrin (PE) (clone JDC10, Southern Biotech), anti-human IgG1-PE (clone 4E3, Abcam), or anti-human IgG4-PE (clone HP6025, Abcam) to measure total or subclass antigen-specific antibodies. Samples were subsequently analyzed on a Luminex FlexMAP 3D instrument (Luminex Corp.). PT-, PRN-, and FHA -specific IgG-positive beads were calculated as IU/ $\mathrm{ml}$ based on the WHO reference serum and TT-specific IgG-positive beads calculated as standardized international units based on diluted TT antibody standards. Other antigen-specific IgGs that had no reference standard or antigen-specific IgG1- or IgG4-positive beads are reported as $\mathrm{AU} / \mathrm{ml}$ and were calculated as the median fluorescent intensity (MFI) over total IgG, IgG1, or IgG4, as previously reported (21). For each sample, total serum IgG, IgE, IgG1, and IgG4 were measured via ELISA through Thermo Fisher's Ready-Set-Go kits for each antibody isotype and subclass.

$B$ cell ELISpot assay. Freshly collected PBMCs were assayed for memory B cell responses at day 7 after Tdap boost, as previously described (90). Briefly, multiscreen 96-well plates were antigen coated with $10 \mu \mathrm{g} /$ well of all pertussis antigens combined and anti-IgG and the coating antibody were diluted in PBS. PBMCs were then added in triplicate to wells $\left(2 \times 10^{5}\right.$ cells/well $)$ and incubated at $37^{\circ} \mathrm{C}, 5 \%$ $\mathrm{CO}_{2}$ for 16 to 20 hours. After washing with PBS-Tween 20, anti-IgG alkaline phosphatase was added and incubated for 4 hours at room temperature. After washing, alkaline phosphatase substrate was prepared and added to the plate, allowing spots to develop. The reaction was stopped by washing with tap water.

AIM and ICS assays. The AIM assay was previously described (91). This assay detects cells that are activated as a result of antigenspecific stimulation by staining antigen-experienced $\mathrm{CD}^{+} \mathrm{T}$ cells for TCR-dependent upregulation of OX40 and CD25 ( AIM $\left._{25}\right)$ and/ or PD-L1 $\left(\mathrm{AIM}_{\mathrm{PD}}\right)$ after an optimal time of 18 to 24 hours of culture. Briefly, cryopreserved PBMCs were thawed and $1 \times 10^{6}$ cells/condition were immediately cultured together with TT peptide pools $(2 \mu \mathrm{g} / \mathrm{ml})$, pertussis peptide pools $(2 \mu \mathrm{g} / \mathrm{ml})$, or PHA $(10 \mu \mathrm{g} / \mathrm{ml}$; Roche $)$ as a positive control in $5 \%$ human serum (Gemini Bioproducts) for 24 hours. To determine the memory phenotype of responding $\mathrm{T}$ cells, staining for CD45RA and CCR7 markers were performed. For ICS, PBMCs were incubated with pertussis, TT, or CMV/EBV peptide pools for 24 hours. After 20 hours, BFA ( $1 \mu \mathrm{g} / \mathrm{ml}$; BD Biosciences) was added for an additional 4 hours. Cells were then washed, stained for extracellular markers for 30 minutes, and then washed, fixed with $4 \%$ paraformalde- 
hyde, permeabilized with 0.5\% saponin (Sigma-Aldrich), and stained for intracellular IL-4, IL-9, IL-17, and IFN- $\gamma$. A combination of PHA or PMA and ionomycin $(1 \mu \mathrm{g} / \mathrm{ml})$ was used as positive control. Samples for both $\mathrm{AIM}_{25}$ and combined $\mathrm{AIM}_{25}$ and ICS assays were acquired on a BD LSRII Flow Cytometer and analyzed using FlowJo X software. Phenotypic characterization of responding $\mathrm{T}$ cells, including activation, apoptosis, exhaustion, and anergic markers, was performed by similar protocols. All flow cytometry mAb reagents for surface or intracellular staining are listed in Supplemental Table 3.

Cellular proliferation. PBMCs were thawed and cells $\left(1 \times 10^{7}\right.$ cells/ $\mathrm{ml}$ ) were labeled with the CFSE Cell Proliferation Kit (Thermo Scientific) at a final concentration of $10 \mu \mathrm{M}$ and cultured for 6 to 7 days in RPMI media (Omega Scientific) supplemented with 5\% human AB serum (Gemini Bioscience), GlutaMAX (Gibco; Thermo Fisher Scientific), and penicillin/streptomycin (Omega Scientific) and stimulated with TT peptide pools $(2 \mu \mathrm{g} / \mathrm{ml})$, pertussis peptide pools $(2 \mu \mathrm{g} / \mathrm{ml})$, or PHA $(10 \mu \mathrm{g} / \mathrm{ml})$. Rounds of cell division were determined by sequential halving of CFSE-fluorescence intensity after additional surface phenotypic staining was performed (Supplemental Table 3).

RNA-sequencing and software analysis. RNA-sequencing (RNAseq) was performed as previously described (92) using a HiSeq 2500 (Illumina) to obtain $50 \mathrm{bp}$ single-end reads. The resulting RNAseq reads were aligned to the hg19 reference using TopHat (v 1.4.1, library-type fr-secondstrand-C) (93). Genes were annotated according to RefSeq (obtained from the UCSC Genome Browser). The HTSeq-count (-m union -s yes -t exon -i gene_id) program was used to determine the sequencing read coverage per gene. Differentially expressed genes between aP- and wP-primed donors were identified using the Bioconductor package DESeq2 (Cooks filter cutoff) (94). Genes were considered differentially expressed between aP and $\mathrm{wP}$ groups when the DESeq2 analysis resulted in a Benjamini-Hochberg adjusted $P$ value of less than 0.05. A more relaxed cutoff was established considering the 500 genes with the highest difference in expression between the 2 cohorts. PCA was performed using the plotPCA method from the DESeq2 package and considering the top 1,000 most variable genes.

Identification of overrepresented pathways for the differentially expressed gene set was performed using the web tool GSEA (95). To determine possible relationships among the genes represented in the
GSEA enriched pathways, the core analysis from IPA software (https:// www.qiagenbioinformatics.com/products/ingenuity-pathwayanalysis/) was performed.

Data availability. All RNA-seq data were deposited in the NCBI's Gene Expression Omnibus database (GEO GSE113891) and ImmPort (SDY787).

Statistics. Comparisons between groups were made using the nonparametric 2-tailed unpaired Mann-Whitney $U$ or paired Wilcoxon's test. Prism 5.0 (GraphPad) was used for all of these calculations. Data in all figure parts in which error bars are shown are presented as median \pm interquartile range. $P<0.05$ was considered statistically significant.

Study approval. This study was performed with approval from the Institutional Review Board at La Jolla Institute for Allergy and Immunology (protocols VD-101-0513 and VD-059-0813). All participants provided written informed consent for participation.

\section{Author contributions}

RDSA, B Peters, B Pulendran, and AS participated in the design and planning of the study. RDSA, MB, CC, NK, AJM, CDP, and LAP performed and analyzed experiments. GS and PV prepared RNA-seq libraries and coordinated RNA-seq. MC gave technical advice. $\mathrm{MB}$ conducted bioinformatics analyses. SC gave critical advice. RDSA, MB, CDP, LAP, and AS wrote the article. All authors read, edited, and approved the manuscript.

\section{Acknowledgments}

This work was supported by the following grants: National Institute of Allergy and Infectious Diseases HHSN272200900044C, NIH U19 AI118626, and NIH S10OD016262. We are grateful to Gaby Smits and Fiona van der Klis (Netherlands National Institute for Public Health and the Environment) for performing tetanus antibody assays. The authors would also like to thank all donors that participated in the study and the clinical studies group staff, particularly Shariza Bautista, Krystal Caluza, Brittany Schwan, and Gina Levi, for all the invaluable help.

Address correspondence to: Alessandro Sette, La Jolla Institute for Allergy and Immunology, 9420 Athena Circle, La Jolla, California 92037, USA. Phone: 858.752.6916; Email: alex@lji.org.
1. Epidemiology and Prevention of VaccinePreventable Diseases. CDC Website. https:// www.cdc.gov/vaccines/pubs/pinkbook/pert. html. Accessed June 22, 2018.

2. Fulton TR, Phadke VK, Orenstein WA, Hinman AR, Johnson WD, Omer SB. Protective effect of contemporary pertussis vaccines: a systematic review and meta-analysis. Clin Infect Dis. 2016;62(9):1100-1110.

3. Sheridan SL, Frith K, Snelling TL, Grimwood $\mathrm{K}$, McIntyre $\mathrm{PB}$, Lambert SB. Waning vaccine immunity in teenagers primed with whole cell and acellular pertussis vaccine: recent epidemiology. Expert Rev Vaccines. 2014;13(9):1081-1106.

4. Zhang L, Prietsch SO, Axelsson I, Halperin SA. Acellular vaccines for preventing whooping cough in children. Cochrane Database Syst Rev. 2014;2014(9):CD001478.

5. Snyder J, Fisher D. Pertussis in childhood. Pediatr
Rev. 2012;33(9):412-420.

6. Conrad DA, Jenson HB. Using acellular pertussis vaccines for childhood immunization. Potential benefits far outweigh potential risks. Postgrad Med.1999;105(7):165-168.

7. Clark TA. Changing pertussis epidemiology: everything old is new again. JInfect Dis. 2014;209(7):978-981.

8. Saadatian-Elahi M, et al. Pertussis: biology, epidemiology and prevention. Vaccine. 2016;34(48):5819-5826.

9. Sealey KL, Belcher T, Preston A. Bordetella pertussis epidemiology and evolution in the light of pertussis resurgence. Infect Genet Evol. 2016;40:136-143.

10. Tan T, et al. Pertussis across the globe: recent epidemiologic trends from 2000 to 2013. Pediatr Infect Dis J. 2015;34(9):e222-e232.

11. van Gent M, Bart MJ, van der Heide HG, Heuvel- man KJ, Mooi FR. Small mutations in Bordetella pertussis are associated with selective sweeps. PLoS One. 2012;7(9):e46407.

12. Burdin N, Handy LK, Plotkin SA. What is wrong with pertussis vaccine immunity? The problem of waning effectiveness of pertussis vaccines. Cold Spring Harb Perspect Biol. 2017;9(12):a029454.

13. Diavatopoulos DA, Edwards KM. What is wrong with pertussis vaccine immunity? Why immunological memory to pertussis is failing. Cold Spring Harb Perspect Biol. 2017;9(12):a029553.

14. Gill C, Rohani P, Thea DM. The relationship between mucosal immunity, nasopharyngeal carriage, asymptomatic transmission and the resurgence of Bordetella pertussis. F1000Res. 2017;6:1568.

15. Warfel JM, Edwards KM. Pertussis vaccines and the challenge of inducing durable immunity. Curr Opin Immunol. 2015;35:48-54. 
16. Aase A, et al. Anti-pertussis antibody kinetics following DTaP-IPV booster vaccination in Norwegian children 7-8 years of age. Vaccine. 2014;32(45):5931-5936.

17. Halperin BA, et al. Kinetics of the antibody response to tetanus-diphtheria-acellular pertussis vaccine in women of childbearing age and postpartum women. Clin Infect Dis. 2011;53(9):885-892.

18. McIntyre PB, Turnbull FM, Egan AM, Burgess MA, Wolter JM, Schuerman LM. High levels of antibody in adults three years after vaccination with a reduced antigen content diphtheriatetanus-acellular pertussis vaccine. Vaccine. 2004;23(3):380-385.

19. Teunis PF, van der Heijden OG, de Melker HE, Schellekens JF, Versteegh FG, Kretzschmar ME. Kinetics of the IgG antibody response to pertussis toxin after infection with B. pertussis. Epidemiol Infect. 2002;129(3):479-489.

20. Watanabe M, Connelly B, Weiss AA. Characterization of serological responses to pertussis. Clin Vaccine Immunol. 2006;13(3):341-348.

21. van der Lee S, Sanders EAM, Berbers GAM, Buisman AM. Whole-cell or acellular pertussis vaccination in infancy determines IgG subclass profiles to DTaP booster vaccination. Vaccine. 2018;36(2):220-226.

22. Le T, et al. Immune responses and antibody decay after immunization of adolescents and adults with an acellular pertussis vaccine: the APERT Study. J Infect Dis. 2004;190(3):535-544.

23. Dalby T, Petersen JW, Harboe ZB, Krogfelt KA. Antibody responses to pertussis toxin display different kinetics after clinical Bordetella pertussis infection than after vaccination with an acellular pertussis vaccine. J Med Microbiol. 2010;59(pt 9):1029-1036.

24. Heininger U, Cherry JD, Stehr K. Serologic response and antibody-titer decay in adults with pertussis. Clin Infect Dis. 2004;38(4):591-594.

25. Barnard A, Mahon BP, Watkins J, Redhead K, Mills KH. Th1/Th2 cell dichotomy in acquired immunity to Bordetella pertussis: variables in the in vivo priming and in vitro cytokine detection techniques affect the classification of T-cell subsets as Th1, Th2 or Th0. Immunology. 1996;87(3):372-380.

26. Warfel JM, Merkel TJ. Bordetella pertussis infection induces a mucosal IL-17 response and long-lived Th17 and Th1 immune memory cells in nonhuman primates. Mucosal Immunol. 2013;6(4):787-796.

27. Warfel JM, Zimmerman LI, Merkel TJ. Acellular pertussis vaccines protect against disease but fail to prevent infection and transmission in a nonhuman primate model. Proc Natl Acad Sci U S A. 2014;111(2):787-792.

28. Rowe J, et al. Antigen-specific responses to diphtheria-tetanus-acellular pertussis vaccine in human infants are initially Th2 polarized. Infect Immun. 2000;68(7):3873-3877.

29. Rowe J, et al. Th2-associated local reactions to the acellular diphtheria-tetanus-pertussis vaccine in 4- to 6-year-old children. Infect Immun. 2005;73(12):8130-8135.

30. Ryan EJ, Nilsson L, Kjellman N, Gothefors L, Mills KH. Booster immunization of children with an acellular pertussis vaccine enhances Th2 cytokine production and serum $\operatorname{IgE}$ responses against pertussis toxin but not against common allergens. Clin Exp Immunol. 2000;121(2):193-200.

31. Ausiello CM, Urbani F, la Sala A, Lande R, Cassone A. Vaccine- and antigen-dependent type 1 and type 2 cytokine induction after primary vaccination of infants with whole-cell or acellular pertussis vaccines. Infect Immun. 1997;65(6):2168-2174.

32. Chiappini E, Stival A, Galli L, de Martino M. Pertussis re-emergence in the post-vaccination era. BMC Infect Dis. 2013;13:151.

33. Edwards KM, Berbers GA. Immune responses to pertussis vaccines and disease. J Infect Dis. 2014;209(suppl 1):S10-S15.

34. Plotkin SA. The pertussis problem. Clin Infect Dis. 2014;58(6):830-833.

35. van der Lee S, Hendrikx LH, Sanders EAM, Berbers GAM, Buisman AM. Whole-cell or acellular pertussis primary immunizations in infancy determines adolescent cellular immune profiles. Front Immunol. 2018;9:51.

36. Gambhir M, Clark TA, Cauchemez S, Tartof SY, Swerdlow DL, Ferguson NM. A change in vaccine efficacy and duration of protection explains recent rises in pertussis incidence in the United States. PLoS Comput Biol. 2015;11(4):e1004138.

37. Gu XX, et al. Waning immunity and microbial vaccines-workshop of the national institute of allergy and infectious diseases. Clin Vaccine Immunol. 2017;24(7):e00034-17.

38. Higgs R, Higgins SC, Ross PJ, Mills KH. Immunity to the respiratory pathogen Bordetella pertussis. Mucosal Immunol. 2012;5(5):485-500.

39. van Twillert I, Han WG, van Els CA. Waning and aging of cellular immunity to Bordetella pertussis. Pathog Dis. 2015;73(8):ftv071.

40. Sheridan SL, Ware RS, Grimwood K, Lambert SB Number and order of whole cell pertussis vaccines in infancy and disease protection. JAMA. 2012;308(5):454-456.

41. Schwartz KL, et al. Effectiveness of pertussis vaccination and duration of immunity. CMAJ. 2016;188(16):E399-E406.

42. Witt MA, Arias L, Katz PH, Truong ET, Witt DJ. Reduced risk of pertussis among persons ever vaccinated with whole cell pertussis vaccine compared to recipients of acellular pertussis vaccines in a large US cohort. Clin Infect Dis. 2013;56(9):1248-1254.

43. Bancroft T, et al. Th1 versus Th2 T cell polarization by whole-cell and acellular childhood pertussis vaccines persists upon re-immunization in adolescence and adulthood. Cell Immunol. 2016;304-305:35-43.

44. Warfel JM, Zimmerman LI, Merkel TJ. Comparison of three whole-cell pertussis vaccines in the baboon model of pertussis. Clin Vaccine Immunol. 2016;23(1):47-54.

45. Misiak A, Wilk MM, Raverdeau M, Mills KH. IL-17-producing innate and pathogen-specific tissue resident memory $\gamma \delta$ T cells expand in the lungs of bordetella pertussis-infected mice. J Immunol. 2017;198(1):363-374.

46. Ross PJ, et al. Relative contribution of Th1 and Th17 cells in adaptive immunity to Bordetella pertussis: towards the rational design of an improved acellular pertussis vaccine. PLoS Pathog. 2013;9(4):e1003264.

47. Devos S, Cormont F, Vrtala S, Hooghe-Peters E, Pirson F, Snick J. Allergen-induced interleukin-9 production in vitro: correlation with atopy in human adults and comparison with interleukin-5 and interleukin-13. Clin Exp Allergy. 2006;36(2):174-182.

48. Kaplan MH, Hufford MM, Olson MR. The development and in vivo function of T helper 9 cells. Nat Rev Immunol. 2015;15(5):295-307.

49. Koch S, Sopel N, Finotto S. Th9 and other IL-9-producing cells in allergic asthma. Semin Immunopathol. 2017;39(1):55-68.

50. Licona-Limón P, et al. Th9 cells drive host immunity against gastrointestinal worm infection. Immunity. 2013;39(4):744-757.

51. Lu Y, et al. Th9 cells promote antitumor immune responses in vivo. JClin Invest. 2012;122(11):4160-4171.

52. Xie J, et al. Elevated antigen-driven IL-9 responses are prominent in peanut allergic humans. PLoS One. 2012;7(10):e45377.

53. Jin L, Williamson A, Banerjee S, Philipp I, Rape M. Mechanism of ubiquitin-chain formation by the human anaphase-promoting complex. Cell. 2008;133(4):653-665.

54. Tang Z, et al. APC2 Cullin protein and APC11 RING protein comprise the minimal ubiquitin ligase module of the anaphase-promoting complex. Mol Biol Cell. 2001;12(12):3839-3851.

55. Krebs J, Klemenz R. The ALG-2/AIP-complex, a modulator at the interface between cell proliferation and cell death? A hypothesis. Biochim Biophys Acta . 2000;1498(2-3):153-161.

56 . $\mathrm{Li}$ J, et al. Caspase-11 regulates cell migration by promoting Aip1-Cofilin-mediated actin depolymerization. Nat Cell Biol. 2007;9(3):276-286.

57. Hamid R, Brandt SJ. Transforming growth-inter acting factor (TGIF) regulates proliferation and differentiation of human myeloid leukemia cells. Mol Oncol. 2009;3(5-6):451-463.

58. Melhuish TA, Gallo CM, Wotton D. TGIF2 interacts with histone deacetylase 1 and represses transcription. J Biol Chem. 2001;276(34):32109-32114.

59. Ichiyama K, et al. Gfi1 negatively regulates $\mathrm{T}(\mathrm{h}) 17$ differentiation by inhibiting RORgammat activity. Int Immunol. 2009;21(7):881-889.

60. Zhu J, et al. Down-regulation of Gfi-1 expression by TGF-beta is important for differentiation of Th17 and CD103+ inducible regulatory T cells. J Exp Med.2009;206(2):329-341.

61. de Rond L, et al. Identification of pertussisspecific effector memory T cells in preschool children. Clin Vaccine Immunol. 2015;22(5):561-569.

62 . Smits K, et al. Different $\mathrm{T}$ cell memory in preadolescents after whole-cell or acellular pertussis vaccination. Vaccine. 2013;32(1):111-118.

63. van Twillert I, Bonačić Marinović AA, Kuipers $B$, van Gaans-van den Brink JA, Sanders EA, van Els CA. Impact of age and vaccination history on long-term serological responses after symptomatic $B$. pertussis infection, a high dimensional data analysis. Sci Rep. 2017;7:40328.

64. Fedele G, et al. Parents as source of pertussis transmission in hospitalized young infants. Infection. 2017;45(2):171-178.

65. Yoshimura A, Muto G. TGF- $\beta$ function in immune 
suppression. Curr Top Microbiol Immunol. 2011;350:127-147.

66. Wilk MM, Misiak A, McManus RM, Allen AC, Lynch MA, Mills KHG. Lung CD4 tissue-resident memory $\mathrm{T}$ cells mediate adaptive immunity induced by previous infection of mice with Bordetella pertussis. J Immunol. 2017;199(1):233-243.

67. Schure RM, et al. Differential T- and B-cell responses to pertussis in acellular vaccine-primed versus whole-cell vaccine-primed children 2 years after preschool acellular booster vaccination. Clin Vaccine Immunol. 2013;20(9):1388-1395.

68. van der Lee S, et al. Robust humoral and cellular immune responses to pertussis in adults after a first acellular booster vaccination. Front Immunol. 2018;9:681.

69. Kemeny DM, Macary PA. The growing complexity of TGF- $\beta$ as a T-cell regulator. Immunology. 2005;114(4):459-460.

70. Sallusto F. Heterogeneity of human CD4(+) T cells against microbes. Annu Rev Immunol. 2016;34:317-334.

71. Zheng SG. Regulatory T cells vs Th17: differentiation of Th17 versus Treg, are the mutually exclusive? Am JClin Exp Immunol. 2013;2(1):94-106.

72. Brown NG, et al. Mechanism of polyubiquitination by human anaphase-promoting complex: RING repurposing for ubiquitin chain assembly. Mol Cell. 2014;56(2):246-260.

73. Schreiber A, et al. Structural basis for the subunit assembly of the anaphase-promoting complex. Nature. 2011;470(7333):227-232.

74. Querec T, et al. Yellow fever vaccine YF-17D activates multiple dendritic cell subsets via TLR2, 7, 8 , and 9 to stimulate polyvalent immunity. J Exp Med. 2006;203(2):413-424.

75. Ravindran R, et al. Vaccine activation of the nutrient sensor GCN2 in dendritic cells enhances antigen presentation. Science. 2014;343(6168):313-317.

76. Geeraedts F, et al. Superior immunogenicity of inactivated whole virus $\mathrm{H} 5 \mathrm{~N} 1$ influenza vaccine is primarily controlled by Toll-like receptor signalling. PLoS Pathog. 2008;4(8):e1000138.

77. Koyama S, et al. Plasmacytoid dendritic cells delineate immunogenicity of influenza vaccine subtypes. Sci Transl Med. 2010;2(25):25ra24.

78. Madura Larsen J, Benn CS, Fillie Y, van der Kleij D, Aaby P, Yazdanbakhsh M. BCG stimulated dendritic cells induce an interleukin-10 producing T-cell population with no $\mathrm{T}$ helper 1 or $\mathrm{T}$ helper 2 bias in vitro. Immunology. 2007;121(2):276-282.

79. da Silva Antunes R, et al. Definition of human epitopes recognized in tetanus toxoid and development of an assay strategy to detect ex vivo tetanus $\mathrm{CD}^{+} \mathrm{T}$ cell responses. PLoS One. 2017;12(1):e0169086.

80. David S, Vermeer-de Bondt PE, van der Maas NA. Reactogenicity of infant whole cell pertussis combination vaccine compared with acellular pertussis vaccines with or without simultaneous pneumococcal vaccine in the Netherlands. Vaccine. 2008;26(46):5883-5887.

81. Halperin S, Scheifele D, Macdonald N. Acellular versus whole-cell pertussis vaccines. Can J Infect Dis. 1992;3(2):57-58.

82. Long SS, Deforest A, Smith DG, Lazaro C, Wassilak GF. Longitudinal study of adverse reactions following diphtheria-tetanus-pertussis vaccine in infancy. Pediatrics. 1990;85(3):294-302.

83. DeAngelis $\mathrm{H}$, Scarpino SV, Fitzpatrick MC, Galvani AP, Althouse BM. Epidemiological and economic effects of priming with the whole-cell Bordetella pertussis vaccine. JAMA Pediatr. 2016;170(5):459-465.

84. Carrasco Pro S, et al. Automatic generation of validated specific epitope sets. JImmunol Res. 2015;2015:763461.

85. Arlehamn CS, et al. Dissecting mechanisms of immunodominance to the common tuberculosis antigens ESAT-6, CFP10, Rv2031c (hspX), Rv2654c (TB7.7), and Rv1038c (EsxJ). J Immunol. 2012;188(10):5020-5031.

86. Schulten V, et al. Previously undescribed grass pol- len antigens are the major inducers of $\mathrm{T}$ helper 2 cytokine-producing $\mathrm{T}$ cells in allergic individuals. Proc Natl Acad Sci U S A. 2013;110(9):3459-3464

87. Weiskopf D, et al. Dengue virus infection elicits highly polarized $\mathrm{CX} 3 \mathrm{CR} 1^{+}$cytotoxic $\mathrm{CD} 4^{+} \mathrm{T}$ cells associated with protective immunity. Proc Natl Acad Sci U S A. 2015;112(31):E4256-E4263.

88. Böyum A. Isolation of mononuclear cells and granulocytes from human blood. Isolation of monuclear cells by one centrifugation, and of granulocytes by combining centrifugation and sedimentation at $1 \mathrm{~g}$. Scand J Clin Lab Invest Suppl. 1968;97:77-89.

89. van Gageldonk PG, van Schaijk FG, van der Klis FR, Berbers GA. Development and validation of a multiplex immunoassay for the simultaneous determination of serum antibodies to Bordetella pertussis, diphtheria and tetanus. JImmunol Methods. 2008;335(1-2):79-89.

90. Jahnmatz M, Kesa G, Netterlid E, Buisman AM, Thorstensson R, Ahlborg N. Optimization of a human IgG B-cell ELISpot assay for the analysis of vaccine-induced B-cell responses. J Immunol Methods. 2013;391(1-2):50-59.

91. Dan JM, et al. A cytokine-independent approach to identify antigen-specific human germinal center $t$ follicular helper cells and rare antigenspecific $\mathrm{CD} 4^{+} \mathrm{T}$ cells in blood. J Immunol. 2016;197(3):983-993.

92. Seumois G, et al. Transcriptional profiling of Th2 cells identifies pathogenic features associated with asthma. J Immunol. 2016;197(2):655-664.

93. Trapnell C, Pachter L, Salzberg SL. TopHat: discovering splice junctions with RNA-seq. Bioinformatics. 2009;25(9):1105-1111.

94. Love MI, Huber W, Anders S. Moderated estimation of fold change and dispersion for RNA-seq data with DESeq2. Genome Biol. 2014;15(12):550.

95. Subramanian A, et al. Gene set enrichment analysis: a knowledge-based approach for interpreting genome-wide expression profiles. Proc Natl Acad SciUS A. 2005;102(43):15545-15550. 